\title{
THE INFLUENCE OF THE EMOTIONAL INTELIGENCE IN PROTECTION OF THE MENTAL HEALTH IN CONDITIONS OF A PSYCHOSOCIAL STRESS
}

\author{
Dr. Lupco Kevereski, Faculty of Education-Bitola \\ E-mail: kever@mt.net.mk \\ Dr. Marija Kotevska Dimovska, Biznis Akademija Smilevski, MSU,G. R. Derzavin“ Bitola \\ E-mail: marijadimovski@yahoo.com \\ Dragan Ristevski, SS Josip Broz Tito-Bitola \\ E-mail: draganris@yahoo.com
}

\author{
A R T I C L E IN F O \\ Original Article \\ Received: Ferburary, 17.2016. \\ Revised: May, 25.2016. \\ Accepted: May, 30.2016. \\ doi:10.5937/IJCRSEE1601017K \\ UDK 159.942.072:613.86
}

\section{Keywords:}

stress,

emotional intelligence,

mental health.

\begin{abstract}
A B S T R A C T
If our time is stressful, than protecting and promoting of our mental health is imperative of the time that is coming. In modern literature there is a huge interest for the determination of the mental health of the emotional intelligence, which is treated as a factor for it's keeping and development. This paper is based on the assumption that the emotional intelligence has considerable contribution for understanding the relationship between psychosocial stress and mental health, seen through three important variables: self-confidence, depression and aggressiveness. In the research were included 72 people, and for variables' measurement are used: questionnaire for measuring emotional intelligence (PK-45), stress inventory and questionnaire for emotional structure of the person- Profile index of emotions. The results from the regressive analyses showed that stress is connected to the three indicators of the mental health. People with low emotional intelligence react with lower self-confidence and high depression and aggressiveness in stressful situations. The two competencies of emotional intelligence (EI) - self consciousness and social consciousness statistically are different from the other relevant measures which show that EI is important thing in understanding the relationship between the stress and mental health.
\end{abstract}

(C) 2016 IJCRSEE. All rights reserved.

\section{INTRODUCTION}

The preservation of our life and health are in direct dependence from constancy storage of our inner psychological balance, i.e., homeostasis balance in terms of the continuing challenges of the changing environment (Bernard, 1961). The famous authority of the area of study of stress Halls use the term "stress" to present the effects of the are what seriously threatens the homeostasis imbalance of the body. According to him, the real or perceived threat to the organism are called

Corresponding Author

PhD Lupco Kevereski, Faculty of Education-Bitola E-mail: kever@mt.net.mk

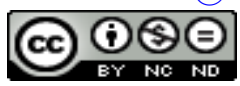

This work is licensed under a Creative Commons Attribution 4.0 International license. The article is published with Open Access at www.ijcrsee.com "stressor", and the reaction to which leads is the "response to stress" (Selye, 1956). A1though responses to stress are adaptive processes, Sally noticed that extension responses to stress can lead to various kinds of diseases. The adverse effects of chronic stress on health are increasing, due to the challenges of modern living which abound with a wide range of adverse living and working conditions.

The relationship between the levels stress and chronic diseases is complex. He is under the influence of the stressor, as well as at the individual (genetic structure and learned patterns of coping). This paper focuses on some psychological factors in dealing with stress.

The primary objective of this paper is to elaborate on the relationship between stress and mental health, as well as to assess the role of emotional intelligence in this context. Numerous researchers (Lazarus and Folkman, 1984, Goleman,1998, Kessing et al., 2003), 
believe that people who are skilled in regulating own and others emotions may be better able to protect themselves from the negative effects of stress, report less depression, aggression and higher self-esteem, (Hammen, 2005).

\subsection{Sanity and pressure}

There are numerous studies that provide valid indicators for the consequences of stress on mental health among different age levels. Numerous studies have shown that exposure to intense and chronic stressors during the developmental years has long-lasting neurobiological consequences and increases the risk for anxiety and depression, problems with control of aggressiveness, hypo-immune dysfunction, structural changes in the CNS and early death, (Shaw 2003). As the most frequent stressors in children and adolescents are indicated: violence, abuse and marital conflicts, (Cicchetti, D. and Toth, S. L., 1995).

As a very frequent psychological consequences of stress in the mature years are listed anxiety and depression. It is known that the first depressive episodes developed after the onset of significant negative life events. There is evidence that stressful life events are the cause for the onset of depression (Hammen, 2005). A study with 13006 patients in Denmark, who had diagnosted depression, showed the stressful events that predating almost before the emergence of difficulty, such as: separation, unemployment,swizz from a close relative, in relation to the control group (Kessing et al., 2003). The diagnosis of a more serious medical illness are considered to be a heavy stress and is often accompanied by high rates of depression (Kessing et al., 2003).

\subsection{EMOTIONAL COMPETENCE AS PROTECTIVE FACTORS IN RESPONSES TO STRESS}

The reactions of the stress events as well as the consequences of them may vary depending on personal and environmental factors. Personal risk factors for the emergence of depression after a serious life event, a disaster or trauma include prior psychiatric history, the symptoms of neurotic, emotional immaturity,social isolation, and other variables (Kessing et al., 2003).

Protective factors that are identified include, social maturity, self-confidence, op- timism and emotional competence. Pruessner showed that people with higher self-esteem had improved responses to acute stress (Pruessner et al., 1999). According to Goleman, emotional intelligence is the potential of the individual for self-awareness, self-confidence, autocrasy and social skills, which are a prerequisite for the preservation of mental health in stressful situations (Goleman, 1995). The concept of emotional intelligence is a contemporary psychological paradigm which unites two aspects of personality such as:heat or intelligence and emotion. Mayer and Salowey are the authors who introduced the concept in the psychological literature, looking at emotional intelligence as a set of skills related to processing of emotionally relevant information. Towards the middle of the nineties Goleman it was popularised the concept of emotional intelligence, has pointed out the importance in everyday life of each person and he define emotional intelligence: «Emotional intelligence consists of the competencies and skills that affect the ability of the person successfully overcomes the challenges of everyday life» (Goleman, 1995). According to Goleman emotional intelligence is the basis on which and appropriate approach to develop the emotional competencies or skills. The author lists the eighteen emotional competencies of emotional intelligence that could be used in different situations (Goleman 1998).

\subsection{Psychological interventions in the prevention of mental disorders in stressful situations}

Psychological interventions in dealing with stressful situations, such as the development of emotional and social competence, can have a positive effect on the preservation of the mental health (Goleman, 1995). One of the indicators of mental health is depression, the widespread disorder with a tendency of increase of the global level (Hammen, 2005). This mental disorder is associated with disruptions in social assessments, difficulties in school, loss of job, physical diseases, lead to unsatisfactory marital relations, a sense of hopelessness (Hammen, 2005). One of the major predecessors of the depression is life stress and daily hassles, (Lazarus and Folkman, 1984).Each of the key questions of psychological interventions for the protection of mental health are: are our emotions and our responses during stressful events are associated with mental, cardiac and other diseases? 
How can we reduce or control stress? Whether emotional intelligence inflect the relationship between stress and mental health, measured with low self-confidence, depression, and aggressive behavior?

There is some preliminary evidence showing that psychological interventions on the development of emotional and social skills can protect people from stress and lead to better adaptation. I.e. emotional intelligence helps people in protection from the harmful effects of stress on mental health. For example,expertise governance or management of emotions is associated with the tendency to hold experimentally caused a positive mood, which has implications for the prevention of depressive conditions (Goleman, 1995). There are other studies that indicate that adolescents who say they are good at managing others emotions tend to have more social support and be more satisfied with it support, which can help in the protection against depression, aggressive outbursts, and thoughts of low personal value (Pruessner et al., 1999).

\section{MATERIALS AND METHODS}

The subject in this research was to examine the role of emotional intelligence on stress and its impact on mental health. The aim of the paper is to investigate whether the competencies of emotional intelligence: self-evaluation, self-regulation and social awareness (which includes regulation of the emotions of others) helps people in protection from the harmful effects of stress.In the paper it moves from a general assumption that people with a high level of emotional intelligence will be less under the influence of the stress from those with low-level, but also that adequately will react to stress without the major disorders of mental health. The primary research question in this thesis reads as follows: the extent to which emotional intelligence, represented by the competencies self-awareness, emotional, and social regulation is a moderator of the relationship between stress and mental health? It is necessary to assess whether the ability for self-evaluation, for the management of their own emotions and those of others will protect people from the negative effects of stress. It is estimated, also, the degree of influence of each of the competencies individually. Whether emotional awareness, when it is not supported by expertise autocrasy increases the sensitivity of people towards stress. The sample in this research consists of 72 participants - 32 female and 40 male, with average age of 28,6 $(\mathrm{SD}=5,0)$. Variables of the research are: mental health - the dependent variable, stress - independent variable and emotional intelligence as a moderator who mediates between the two variables. From the spectrum of the psychodiagnostician instrumentarium was used the battery of implement and questionnaires which are a function of the measurement of the basic variables in the paper such as: Profile index of emotions DRINK, (Baskovic et al., 1985). Questionnaire the emotional competence PECK-45 (Takšic, 1998). The scale of psychological stress - YES, inventory of 49 statements, rated on a scale from 1 to 8 , where 1 is "not at all" and 8 is "extremely". The organization of the research was in the first half of 2015, while the research was conducted in the period September - December. 2015 in the municipality of Bitola. Statistical processing of data was made with the help of the SPSS program package.

Table 1. Correlation and intercorrelation between the variables of emotional intelligence: emotional awareness (EA), emotional regulation (ER), stress (S) and the variables of mental health: aggressiveness (A), confidence (C) and depravation (D)

\begin{tabular}{lcccccc}
\hline & EC & EB & Pressure & A & C & D \\
\hline EC & 1 & $0,40^{* * *}$ & 0,15 & 0,21 & 0,199 & 0,19 \\
\hline EB & - & $\mathbf{1}$ & 0,09 & -0.12 & $-0,16$ & $-0,017$ \\
\hline Pressure & - & & $\mathbf{1}$ & $\mathbf{0 , 4 1 * * *}$ & $\mathbf{0 , 3 3 * *}$ & $\mathbf{0 , 6 7 * *}$ \\
\hline A & & & & 1 & $-0,35^{* *}$ & $0,44^{* * *}$ \\
\hline $\mathbf{C}$ & & & & & 1 & $0,36^{* * *}$ \\
\hline $\mathbf{D}$ & & & & & & 1 \\
\hline
\end{tabular}




\section{RESULTS AND DISCUSSION}

To assess whether emotional intelligence, represented by the competencies of emotional awareness, self-regulation and so- cial regulation (the rule with their emotions and the emotions of others), is a capability in the relationship between stress and mental health, we used the hierarchical regression analysis.

Table 2. Correlations between stress and depravation, aggressiveness and confidence among the participants with low and high emotional intelligence.

\begin{tabular}{lccccc}
\hline \multirow{2}{*}{$\begin{array}{c}\text { Relation with } \\
\text { pressure }\end{array}$} & \multicolumn{2}{c}{ Low emotional intelligence } & \multicolumn{2}{c}{$\begin{array}{c}\text { High emotional } \\
\text { intelligence }\end{array}$} \\
\cline { 2 - 6 } & $\begin{array}{c}\text { Correlation } \\
\text { coefficient } \mathrm{r}\end{array}$ & $\begin{array}{c}\text { Determinant } \\
\text { coefficient } \mathbf{R}\end{array}$ & $\begin{array}{c}\mathrm{K} . \\
\text { alienation }\end{array}$ & $\begin{array}{c}\text { Correlation } \\
\text { coefficient } \mathrm{r}\end{array}$ & $\begin{array}{c}\text { Determinant } \\
\text { coefficient } \mathbf{R}\end{array}$ \\
\hline Pressure -mopes & $0,61^{* *}$ & 0,372 & 0,628 & $0,29^{*}$ & 0.084 \\
\hline $\begin{array}{l}\text { Pressure - } \\
\text { aggressivness }\end{array}$ & $0,51^{* *}$ & 0,261 & 0,739 & $0,25^{*}$ & 0.062 \\
\hline $\begin{array}{l}\text { Pressure } \\
\text { confidence }\end{array}$ & $0,44^{* *}$ & 0,194 & 0,806 & 0,14 & 0.019 \\
\hline
\end{tabular}

The results show that the variables of mental health are interconnected, and are also associated with stress. The competencies of emotional intelligence are related among themselves, but not significantly associated with any one variable, and it is a proof of its uniqueness. Emotional intelligence shows minimal correlation with the measures of stress and mental health, which indicates the constructive diversity.

To assess whether emotional intelligence the relationship stress-mental health, used regression analysis. The tested results in the low and high values of emotional intelligence. In table 2 shows that stress is strongly linked with mopes,aggressiveness and low self-esteem among participants with low emotional intelligenceThe interaction between the participants with high emotional intelligence shows that the relationship stress - mental health is a significant, although at lower level, and those with high emotional intelligence (Table 2.). Comparison with the findings of similar studies, as for example the research of Ciarrochi, J., Deane, F. P., and Anderson, S. (2002) indicates that the results are in the similar direction. Correlation of stress with depression among participants with high EI is statistically significant and amounts to $r=0,61$, and in the specified study $r=0,65$. The most important findings in this paper refer to the structural uniqueness of emotional intelligence, which is suggested by the fact that it is not directly related to stress or mental health, i.e. emotional intelligence is not in significant correlation with the stress and indicators of mental health.
This finding substantiates the claim that emotional intelligence is a moderator, i.e. a factor of the ratio stress-mental health.

\section{CONCLUSION}

The findings of this paper are in addition of great interest for the emotional intelligence and its part in the promotion of mental health. They support the argument that the competencies of the constructor are identifiable and useful, which has important implications for understanding the relationship between stress and mental health. In the paper showed that the competencies of emotional intelligence the moderating the relationship between stress and the three investigated variables of mental health: mopes, aggressiveness and level of self-esteem. These findings, which are consistent with the findings of similar research, have important practical implications for understanding the relationship between stress and mental health. The results in this paper show that individuals with low emotional intelligence are inclined in stressful situations, to react with a distortion of mental health, in comparison with individuals with high EI who less show that inclination. This supports the conclusion that the low emotionally intelligent people are in danger to impair their mental health in stressful situations and those with high emotional intelligence will respond to stress with less mopes and aggressiveness. These findings may be useful for actualize of the concept of emotional intelligence and in- 
vestment in the creation and implementation of programs for its development in the function of the save of mental health in crisis situations. The research emphasizes the role of emotional intelligence in promoting mental health. However further research is needed before we can fully accept these findings.

\section{ACKNOWLEDGMENTS}

This paper wouldn't have been compiled together without the moral and intellectual support of teachers and other participants that participated voluntarily in the research.

\section{Conflict of interests}

The authors declare no conflict of interest.

\section{REFERENCE}

Baškovac-Milinković, A., Bele-Potočnik, Ž., Hruševar, B., \& Rojšek, J. (1979). PIE Profil indeks emocija, priručnik. Ljubljana: Zavod SR Slovenije za produktivnost dela Ljubljana, Centar za psihodiagnostična sredstva.

Bernard, C., \& Greene, H. C. (1957). An introduction to the study of experimental medicine. Courier Corporation.

Ciarrochi, J., Deane, F. P., \& Anderson, S. (2002). Emotional intelligence moderates the relationship between stress and mental health. Personality and individual differences, 32(2), 197-209.

Cicchetti, D., \& Toth, S. L. (1995). A developmental psychopathology perspective on child abuse and neglect. Journal of the American Academy of Child \& Adolescent Psychiatry, 34(5), 541-565.

Goleman, D. (1995). Emotional intelligence: Why it can matter more than IQ New York: Bantam Dell.

Goleman, D. (1998). Working with Emotional Intelligence, New York: Bantam Dell.

Hammen, C. (2005). Stress and depression. Annu. Rev. Clin. Psychol., 1, 293-319.

Kessing, L. V., Agerbo, E., \& Mortensen, P. B. (2003). Does the impact of major stressful life events on the risk of developing depression change throughout life?. Psychological medicine, 33(07), 1177-1184.

Lazarus, R. S., \& Folkman, S. (1984). Stress, appraisal, and coping. Springer publishing company.

Pruessner, J. C., Hellhammer, D. H., \& Kirschbaum, C. (1999). Burnout, perceived stress, and cortisol responses to awakening. Psychosomatic medicine, 61(2), 197-204.

Selye, H. (1956). The stress of life. New York: McGraw-Hill.

Shaw, J. A. (2003). Children exposed to war/terrorism. Clinical Child and Family Psychology Review, 6(4), 237-246.

Takšić, V. (1998). Validacija konstrukta emocionalne inteligencije. [Validation of the Emotional Intelligence Construct]. Unpublished doctoral dissertation, University of Zagreb. 